\title{
Review of the British Thoracic Society Winter Meeting 2015, 2-4 December, London, UK
}

\author{
Ricardo J José, ${ }^{1}$ James D Chalmers, ${ }^{2}$ Neil J Greening, ${ }^{3}$ Sam M Janes, ${ }^{4}$ \\ on behalf of the BTS Science and Research Committee
}

'Department of Respiratory Medicine, Homerton University Hospital, London, UK ${ }^{2}$ Division of Molecular and Clinical Medicine, University of Dundee, Dundee, UK ${ }^{3}$ Leicester Respiratory Biomedical Research Unit, Department of Respiratory Medicine, Glenfield Hospital, Institute of Lung Health, University Hospitals of Leicester, Leicester, UK ${ }^{4}$ Lungs for Living Research Centre, UCL Respiratory, University College London, London, UK

\section{Correspondence to} Dr Sam M Janes, Lungs for Living Research Centre, UCL Respiratory, University College London, 5 University Street, London WC1E 6JJ, UK; s.janes@ucl.ac.uk

RJJ, JDC and NJG contributed equally.

Received 7 January 2016 Revised 16 February 2016 Accepted 18 February 2016 Published Online First 25 March 2016

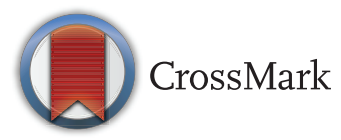

\footnotetext{
To cite: José RJ, Chalmers JD, Greening NJ, et al. Thorax 2016;71: 555-559.
}

\section{ABSTRACT}

The British Thoracic Society Winter Meeting 2015 is reviewed in this article. Over 3 days in December, this annual scientific meeting attracted over 2300 delegates and up-to-date respiratory research was presented by leading UK and international speakers. This article reviews a number of symposia and selected abstract presentations from the meeting.

\section{INTRODUCTION}

Looking out from the sixth floor of the QEII Conference Centre, the magnificent sight of The Shard, the London Eye and Big Ben all in one view reflected the equally outstanding meeting that we were about to experience over 3 days. This year the British Thoracic Society (BTS) Winter Meeting brought over 2300 delegates to London, and provided a forum for clinicians, scientists, allied healthcare professionals and students from the UK and abroad. A total of 146 speakers (27 from overseas) and chairs participated in delivering topical symposia, which complemented presentations from the 460 accepted abstracts (131 in the spoken sessions, 291 posters, 32 moderated posters and 6 for the Early Career Investigator competition).

\section{BTS/British Lung Foundation/British Association for Lung Research Early Career Investigators Symposium}

The BTS/British Lung Foundation (BLF)/British Association for Lung Research (BALR) Early Career Investigators Symposium is an opportunity to see the future of UK respiratory medicine as six young academics present in front of a multidisciplinary judging panel for the opportunity to be named this year's Early Career Investigator winner.

Dr Rachel Dancer (Birmingham University) received the BLF award for demonstrating that vitamin D supplementation reduces extravascular lung water, a surrogate marker of lung injury, after oesophagectomy in the VINDALOO trial $^{1}$ (confirming Birmingham as the home of UK Indian Cuisine after the equally delicious BALTI trial! ${ }^{2}$ ). Her group previously reported that vitamin D deficiency appears to contribute to the development of acute respiratory distress syndrome (ARDS) ${ }^{3}$ and now demonstrate that vitamin $\mathrm{D}$ supplementation reduces perioperative extravascular lung water but not oxygenation. ${ }^{1}$ The immunomodulatory effects of vitamin D (or the absence of them) have been a recurring theme of our 3 years reporting from the BTS Winter Meeting and we look forward to large confirmatory studies. ${ }^{4} 5$ Dr Richard Lee (King's College London) was the runner up in the BLF competition for his study evaluating MET targeted therapy in non-small cell lung cancer. ${ }^{6}$

Dr Aran Singanayagam (Imperial College London) was the recipient of the BALR award for his study demonstrating that inhaled fluticasone caused an outgrowth of new bacteria within the mouse microbiome, particularly Stenotrophomonas spp and was accompanied by impaired clearance of bacteria and viruses. ${ }^{7}$ Given the clinical data linking fluticasone to an increased risk of pneumonia, this seems important and plausible. ${ }^{8}$ We await confirmation in humans. The runner up was $\mathrm{Dr}$ Megan Jackson (Queen's University Belfast) who demonstrated that mesenchymal stem cells can enhance macrophage phagocytosis, suggesting a potential therapeutic role in ARDS. ${ }^{9}$

Finally, the BTS award was won by Dr Alex Rothman (University of Sheffield). He described the role of MicroRNA-140-5p and SMURF1 in experimental and human pulmonary arterial hypertension (PAH) ${ }^{10}$ Low levels of microRNA were associated with pulmonary hypertension in human and animal $\mathrm{PAH}$, while restoring this pathway prevented PAH development in rats. The runner up for the BTS award was Dr Ahsan Akram (University of Edinburgh), who reported a novel in vivo imaging method of detecting bacteria using fluorescent antimicrobial peptides. ${ }^{11}$ The method has the potential to improve the diagnosis of conditions such as ventilator-associated pneumonia where existing diagnostic methodologies are limited and treatment remains largely empirical. ${ }^{12}$

\section{Plenary scientific symposium}

Four of the UK's leading clinician scientists presented their cutting edge translational research during this symposium.

Dr Nicholas Hart (London) started his presentation by highlighting the importance of mentorship, support and encouragement in research. His research showed how patients who are critically ill develop a rapid deterioration in muscle bulk, which is greater in multiorgan failure and he explored its underlying mechanisms. ${ }^{13}$ Additionally, his patient-focused research demonstrates that neural respiratory drive measured by parasternal electromyography is feasible and can detect inpatient deterioration and predict early readmissions in those with chronic obstructive pulmonary disease (COPD) exacerbations. ${ }^{14} 15$

Professor Jacky Smith (Manchester) presented her research into the mechanisms and therapeutics for cough, a common respiratory symptom that is particularly troublesome in smokers. ${ }^{16}$ Her work confirms that neuronal dysfunction is an important 
driver of cough and that specific neuro-phenotypes may exist. ${ }^{17}$ Finally, her group conducted a randomised controlled trial of the P2X3 receptor antagonist (AF-219) and demonstrated that this novel agent reduces cough frequency and is a promising anti-tussive for the future, once the taste disturbances are resolved. $^{18}$

Dr James Chalmers (Dundee) presented his work into neutrophilic inflammation in bronchiectasis. His work shows that increased bacterial load in the airways is associated with increased airway and systemic inflammation, which is associated with exacerbation frequency. ${ }^{19}$ Additionally, he highlighted novel findings that bronchiectasis sputum neutrophils produce extracellular traps, a mechanism for pathogen entrapment and killing, but have reduced phagocytic capacity. These are important findings for our understanding of neutrophil function in the airways where strategies are needed to achieve a fine balance between host defence and neutrophil-associated injury. ${ }^{20}$ Furthermore, James chairs the pan-European network and registry in bronchiectasis (EMBARC) with the support of the European Respiratory Society (ERS), so if any BTS members would like to contribute, please visit http://www.bronchiectasis. eu/register. ${ }^{21}$

Dr Pandurangan Vijayanand (Southampton and La Jolla, California, USA) presented work where his group identified new genes that contribute to asthma by using an unbiased approach. He highlighted areas of the genome that are highly active in diseased cells, but inactive in healthy cells. ${ }^{22}$

\section{BTS President's address/the Moran Campbell lecture}

A unique address from Professor Mike Morgan (Leicester) combined the President's address, as he took over from Professor Ann Millar as BTS President, and the Moran Campbell lecture, an invited lecture celebrating achievements in pulmonary physiology. The talk, 'from pain to gain' emphasised the importance of exercise in lung health both in maintaining health and also in the assessment of pathology, while reflecting on the achievements and life of Moran Campbell himself. ${ }^{23} \mathrm{He}$ then analogised that working with political organisations, commissioners and policy makers, in his role as President may also require a pain to gain approach.

\section{BTS lecture}

This year's BTS lecture was a particular highlight within the programme and received great praise from the conference delegates. Professor Alvar Agusti (Barcelona), board member for the Global Initiative for Chronic Obstructive Lung Disease (GOLD) group, provided insight into the complexity and direction of personalised treatment for COPD. He described the multiple components that contribute to COPD and how COPD populations are heterogeneous with different traits present in individuals. $^{24}$ To address this complexity he proposed we think of a COPD 'control panel' with the different aspects of the disease combining to make multiple different phenotypes. $^{25}$ We were also introduced to the concept of 'treatable traits', those characteristics that are amenable to specific therapy and therefore can be used to influence future outcomes. Identifying these traits is important and there may be practical methods, such as using an individualised patient-focused problem-based approach. $^{26}$

\section{Rare (and not so rare) lung infections}

Primary ciliary dyskinesia was well represented at the BTS Winter Meeting, in the spoken sessions where several highquality abstracts were reported, and by the patient support group present throughout the conference. Dr Shah reported data from 151 adult patients with primary ciliary dyskinesia at a tertiary referral centre in London. Risk factors for lung function decline in relation to severity of disease on high-resolution CT and ciliary ultrastructure, but interestingly were not associated with Pseudomonas aeruginosa colonisation. ${ }^{27}$ P aeruginosa was more common in patients diagnosed late, as was lower lung function, emphasising the importance of picking up the disease early. $^{28}$

Fungal infections are an important cause of morbidity and mortality post transplantation. Our inaugural award for video of the BTS goes to the same Dr Shah who demonstrated lateral transfer of Aspergillus fumigatus from dying macrophages to new cells, a process hindered by calcineurin inhibitors, a standard treatment post transplant. ${ }^{29}$ These inhibitors were shown in a separate abstract to inhibit maturation of dendritic cells, further impairing host defence against $A$ fumigatus infection. ${ }^{30}$

The growing national interest in bronchiectasis was reflected by increased abstract numbers. Koustas et $a l^{31}$ identified no correlation between IL-8, IL-17 and the recently described severity tool, the Bronchiectasis Severity Index, finding no clinical value of these biomarkers. ${ }^{32} P$ aeruginosa had a dedicated session at this year's BTS Winter Meeting, reflecting its importance in driving disease progression in cystic fibrosis (CF) and bronchiectasis. ${ }^{33}$ Interesting data were presented on phage therapy for $\mathrm{CF}^{34}$ the absence of good evidence of cross infection in a UK centre in Exeter, ${ }^{35}$ and evidence from an observational study from Belfast to suggest that the addition of an inhaled antibiotic enhances eradication. ${ }^{36}$

Streptococcus pneumoniae remains an important pathogen in community-acquired pneumonia. ${ }^{37}$ Pneumolysin is a major virulence factor and work presented at the BTS suggests that this pore-forming toxin dampens early inflammation, allowing growth of the bacteria by evasion of the immune system. ${ }^{38}$ Furthermore, challenging humans with $S$. pneumoniae is a useful experimental model to investigate responses to colonisation. Unlike in children in whom colonisation events appear to be symptomatic (although confounding factors may exist), it has now been reported that in adults colonisation events are asymptomatic. $^{39}$

\section{Antibiotic resistance}

Combatting antibiotic resistance is an international priority and this was reflected in a high-profile symposium. Opened by an introduction from Chairs Professor McShane (Oxford) and Dr Forthergill (Liverpool), the symposium heard the latest Public Health England and British Society of Antimicrobial Chemotherapy (BSAC) data from David Livermore (Norwich)S. pneumoniae remains the dominant pathogen in pneumonia, even in patients with frequent healthcare contacts, and resistance remains low. ${ }^{40}$ There are additional causes for optimism, for example in the decline in methicillin-resistant Staphylococcus aureus (MRSA) as a proportion of S. aureus cases in the UK, but an increasing global threat from carbapenemase-resistant Gram negatives and other multidrug-resistant organisms. ${ }^{41}$

Professor Stuart Elborn (Belfast) reviewed the potential role of microbial diagnostics, from PCR to sequencing-based 'microbiome' characterisation and how this could be used to rationalise antibiotic use and to identify resistance. ${ }^{42}{ }^{43} \mathrm{He}$ also demonstrated experiments suggesting that interactions between different species within the microbiome could dramatically change antibiotic susceptibility. For example, Prevotella spp can produce $\beta$ lactamases that protect $P$. aeruginosa from ceftazidime 
treatment in the CF microbiome. ${ }^{44}$ He suggested that traditional methods of defining resistant $(\mathrm{R})$ and sensitive $(\mathrm{S})$ from in vitro growth might not always predict in vivo effectiveness of antibiotics.

Finally, Professor Grant Waterer (Perth, Australia) gave a global view on antibiotic resistance, describing important differences in care that contribute to differences in antibiotic resistance rates internationally. He finished optimistically, suggesting that we remain far from the antibiotic apocalypse, but also challenged the audience to consider that tackling antibiotic resistance would need to include targeting antibiotic prescribing in children. Additionally, we should consider appropriate therapy at a patient's end of life, as multidrug-resistant pathogens is an increasing problem in intensive care units and long-term ventilation facilities at this time.

\section{COPD}

The two major COPD symposia were popular as ever with overflowing rooms. COPDMAP is a large consortium of Medical Research Council and industry partners, supporting close collaboration between some of the top centres in the UK investigating COPD phenotypes, biomarkers and mechanisms, which may lead to new therapeutic targets. Much of the work presented here was novel, providing attendees with the latest in understanding in this field. Professor Donnelly (London) provided evidence that increasing bacterial load is associated with increased airway inflammation, which is in part due to defects in macrophage phagocytosis and efferocytosis. Despite the importance of these sentinel resident phagocytes, the role of alveolar macrophage independent clearance mechanisms during lung infection is often overlooked. ${ }^{45}$ Professor Adcock (London) spoke about the physiological roles of mitochondria, showing multiple roles beyond the traditional model that its only role is for ATP production. He talked about mitochondrial dysfunction, which affects inflammation and proliferation. In the final talk, Professor Polkey (London) took a different steer, looking at one of the systemic effects of COPD in skeletal muscle dysfunction. Here, distinct muscle-specific phenotypes have been described and interventions to understand mitochondrial targets. Finally, he described the programme of activity to inform regulatory bodies about using exercise tests as a recognised outcome in COPD.

The other COPD symposium ran along a theme similar to Professor Agusti's BTS Lecture and focused on 'beyond $\mathrm{FEV}_{1}$ ' in COPD. The first three speakers each covered a different aspect of COPD requiring differing assessment and treatment. Dr Kon (Harefield) spoke about functional measures of COPD, such as exercise capacity ${ }^{46}$ and walking speed. ${ }^{47}$ This is often overlooked as a measure, yet exertional dyspnoea is the symptom that is the hallmark of COPD. Dr Franssen (Maastricht, The Netherlands) presented the importance of comorbidities, in particular cardiovascular risk and lung cancer risk. While the importance of comorbidities has long been recognised, he also showed that groups of comorbidities often coexist with each other. ${ }^{48}$ This is important as screening for all potential comorbidities in every patient is time consuming and expensive, so being able to identify groups allows targeted screening. Dr Bafadhel (Oxford) talked about targeting exacerbations. The different factors triggering an exacerbation have become more apparent over the last few years, ${ }^{49}$ and we are now approaching a time when we give targeted treatment for specific factors, such as steroids only for eosinophilic exacerbations. ${ }^{50} 51$

Away from the major symposia, original research was presented in a number of spoken and poster sessions. Data from a large primary care cohort were used to identify patients with COPD at risk of hospital admission or death, ${ }^{52}$ which may help to find patients who need additional care. Cardiovascular risk in COPD was also a common theme in several sessions, ${ }^{53-55}$ including looking at arterial stiffness. ${ }^{56}$ One pragmatic study, comparing venous and arterial blood gas analysis, and now in press in Thorax, could potentially change our management of COPD exacerbations and improve patient experience. ${ }^{58}$

\section{Lung cancer}

After years in the doldrums, lung cancer is now one of the most exciting areas in pulmonary medicine. Presentations from this year's BTS/British Thoracic Oncology Group Symposium demonstrated revolutionary treatments for lung cancer are emerging, lung cancer will be identified at earlier stages by screening, and that we are moving towards seeing personalised medicine in practice.

Professor Camidge (Denver, Colorado, USA), described lung cancer as an immunogenic tumour ${ }^{59}$ and the emerging role of programmed death 1 axis inhibitors in its treatment. Nivolumab has demonstrated superior overall survival compared with docetaxel as a second-line therapy for squamous and non-squamous advanced non-small cell lung cancer, ${ }^{60}{ }^{61}$ and pembrolizumab has shown impressive response rates and progression-free survival when the tumours express high levels of programmed death ligand $1 .^{62}$ Dr Popat (London) then described the national Strat-Med 2 programme and the linked Matrix trial. In this national programme, over 20 mutations will be targeted with novel therapies. Certainly, targeted therapy will continue to change the way we treat lung cancer. ${ }^{63}$

\section{Pulmonary embolism}

The pulmonary embolism (PE) symposium was well attended and provided delegates with evidence-based guidelines from the 2014 European Society of Cardiology on the diagnosis and management of new $\mathrm{PE}^{64}$ presented by Dr Robin Condliffe (Sheffield). He highlighted the complexity of the algorithms and the use of PE severity index (PESI) to stratify patients. Although systemic thrombolysis is indicated in patients with high-risk PE and haemodynamic compromise, other features suggesting that thrombolysis should be considered include the concurrent detection of deep vein thrombosis and a high blood lactate level. ${ }^{65}$

Dr Pepke-Zaba (Cambridge) gave an interesting talk on the pathobiology of chronic thromboembolic pulmonary hypertension (CTEPH) in which she highlighted the contribution of inflammation and deficiency in angiogenesis to the pathogenesis of CTEPH and the use of PAH-targeted therapies. ${ }^{66}$

The session ended with an enthusiastic debate between Mr David Jenkins (Cambridge) and Dr Irene Lang (Vienna, Austria). Mr Jenkins provided compelling evidence for pulmonary endarterectomy as the treatment of choice in CTEPH, however expert opinion is required to determine operability and surgery should only be done in an experienced centre where the mortality is $<5 \%$. ${ }^{67}$ This treatment is associated with improvement in symptoms and better prognosis. Despite hypothermic circulatory arrest, cognitive function does not decline post surgery. ${ }^{68}$ Dr Lang, in contrast, highlighted balloon angioplasty as a novel interventional option that may be beneficial in a well selected group of patients with CTEPH who are not surgical candidates. $^{69}$

\section{Best of Thorax}

Four presentations showcasing the best of this year's publications in Thorax were given in the 'best of Thorax' symposium. 
This new session, which will become an annual event, presented three diverse subjects in the one session, including mechanisms of idiopathic pulmonary fibrosis (IPF), treatment of multidrug resistant TB (MDR-TB) in Ethiopia, and COPD exacerbations.

Professor Natarajan (Chicago, USA) presented novel mechanistic findings for IPF. Sphingosine-1-phosphate lyase (S1PL) is a bioactive lipid that is key in regulating a number of signalling pathways. ${ }^{70}$ In this study, in humans and mouse models, it was found to be elevated and correlated with disease severity and survival. ${ }^{71}$ This mechanism may lead to new therapeutic targets.

The global importance of MDR-TB was highlighted and with less than $20 \%$ of patients with MDR-TB accessing treatment in 2012. ${ }^{72}$ Professor Goldfeld (Boston, USA) presented the instigation, expansion and results of a standardised second-line drug regime programme in Ethiopia. In approximately 5 years, 1044 patients were treated with treatment success of $78.6 \% .^{73}$ This represents a huge impact on this important problem in a setting with severe resource constraints and diverse geography.

The final two talks were focused on COPD exacerbations. The impact of hospitalisation for an exacerbation of COPD has been well recognised and interventions to reduce readmissions have had mixed results. ${ }^{74} 75$ It is clear that hospitalisation and its impact are a result of the interaction of the underlying condition and the severity of the acute event. ${ }^{76}$ Identifying the response and recovery (short and long term) has always been based around clinical judgement. Dr Suh (Dartford) and Dr Kon (Harefield) presented two simple measures that may aid that clinical decision making. Dr Suh presented measures of neural respiratory drive to measure load on the respiratory system. Using this non-invasive measure he was able to demonstrate recovery, which was superior to other standard measures in predicting patients who were unlikely to be readmitted. ${ }^{15}$ Dr Kon showed that long-term outcome was predicted using a simple walking test on discharge, the $4 \mathrm{~m}$ gait speed, which takes $5 \mathrm{~min}$ to perform. ${ }^{77}$ This global measure of frailty shows the effects of COPD on the whole system. These two measures, and others recently described, ${ }^{78}$ show that identification of individuals at risk of hospital readmission or death following hospitalisation may be a realistic prospect, allowing for targeted intervention.

\section{\#BTSWinter2015}

The new Thorax editors' December editorial highlighted the importance of social media in disseminating information. ${ }^{79}$ From 1 December to 6 December 2015, 2771 tweets were sent with the Twitter hashtag \#BTSWinter2015 by 543 participants at an average of 18 tweets per hour, resulting in 8761002 impressions, demonstrating the impact of this medium to share conference highlights with those in all continents who could not make it to this great scientific meeting. Beyond the conference, following@thoraxbmj will continue to keep everyone updated with the latest publications from the journal and \# resped will be a way to connect on Twitter with respiratory knowledge and education.

\section{Respiratory research for the 21st century}

Finally, Dr Kim Prisk from the North American Space Agency laboratory (San Diego, California, USA) presented the symposium talk 'Occupational disease in the 21st century: space as the final frontier'. His work focuses on understanding the effects of zero gravity on lung function and pulmonary aerosol transport in preparation for the day that may arrive when humans spend more time on the lunar surface. In his entertaining presentation he not only showed some great pictures from outer space but transmitted to the audience the importance of passion and ambition in conducting research. On this note, we look forward to seeing all the stellar research performed by BTS members and colleagues at the BTS Winter Meeting of 2016.

Contributors Attended sessions and wrote the report: RJJ, JDC, NJG and SMJ; drafted the manuscript: RJJ; edited the manuscript for important intellectual content: JDC, NJG and SMJ. SMJ is the corresponding author and is the guarantor.

Competing interests None declared.

Provenance and peer review Not commissioned; externally peer reviewed.

\section{REFERENCES}

1 Dancer $R$, Parekh D, Scott A, et al. T2 vitamin D supplementation reduces perioperative systemic and alveolar inflammation in patients undergoing oesophagectomy: results of the Vindaloo Trial. Thorax 2015;70:A1.

2 Perkins GD, McAuley DF, Thickett DR, et al. The beta-agonist lung injury trial (BALTI): a randomized placebo-controlled clinical trial. Am J Respir Crit Care Med 2006;173:281-7.

3 Dancer RCA, Parekh D, Lax S, et al. Vitamin D deficiency contributes directly to the acute respiratory distress syndrome (ARDS). Thorax 2015;70:617-24.

4 Greening NJ, José RJ, Chalmers JD, et al. Review of the British Thoracic Society Winter Meeting 2014, 3-5 December, London, UK. Thorax 2015;70:278-83.

5 Martineau AR, Hanifa Y, Witt KD, et al. Double-blind randomised controlled trial of vitamin D3 supplementation for the prevention of acute respiratory infection in older adults and their carers (ViDiFlu). Thorax 2015;70:953-60.

6 Lee R, Ortiz-Zapater E, Weitsman G, et al. T6 MET targeted therapy in Lung adenocarcinoma: does 'resistant' EGFR make a MET-responsive dimer? Thorax 2015;70:A3-5.

7 Singanayagam A, Glanville N, Pearson R, et al. T1 Fluticasone propionate alters the resident airway microbiota and impairs anti-viral and anti-bacterial immune responses in the airways. Thorax 2015;70:A1.

8 Singanayagam A, Chalmers JD, Hill AT. Inhaled corticosteroids and risk of pneumonia: evidence for and against the proposed association. QJM 2010;103:379-85.

9 Jackson M, Morrison T, O'Kane C, et al. T3 Mitochondrial transfer is an important mechanism by which mesenchymal stromal cells (MSC) facilitate macrophage phagocytosis in the in vitro and in vivo models of acute respiratory distress syndrome (ARDS). Thorax 2015;70:A1-2.

10 Rothman A, Arnold N, Pickworth J, et al. T5 MicroRNA-140-5p regulates disease phenotype in experimental pulmonary arterial hypertension via SMURF1. Thorax 2015;70:A3.

11 Akram A, Avlonitis N, Vendrell M, et al. T4 Optically detectable antimicrobial peptides enable the immediate detection of bacteria and fungi in the lung. Thorax 2015;70:A2-3.

12 Hellyer TP, Morris AC, McAuley DF, et al. Diagnostic accuracy of pulmonary host inflammatory mediators in the exclusion of ventilator-acquired pneumonia. Thorax 2015;70:41-7.

13 Puthucheary ZA, Rawal J, McPhail M, et al. Acute skeletal muscle wasting in critical illness. JAMA 2013;310:1591-600.

14 Murphy PB, Kumar A, Reilly C, et al. Neural respiratory drive as a physiological biomarker to monitor change during acute exacerbations of COPD. Thorax 2011;66:602-8.

15 Suh ES, Mandal S, Harding R, et al. Neural respiratory drive predicts clinical deterioration and safe discharge in exacerbations of COPD. Thorax 2015;70:1123-30.

16 Sumner $H$, Woodcock $A$, Kolsum $U$, et al. Predictors of objective cough frequency in chronic obstructive pulmonary disease. Am J Respir Crit Care Med 2013;187:943-9.

17 West PW, Canning BJ, Merlo-Pich E, et al. Morphologic characterization of nerves in whole-mount airway biopsies. Am J Respir Crit Care Med 2015;192:30-9.

18 Abdulqawi R, Dockry $R$, Holt $K$, et al. P2X3 receptor antagonist (AF-219) in refractory chronic cough: a randomised, double-blind, placebo-controlled phase 2 study. Lancet 2015;385:1198-205.

19 Chalmers JD, Smith MP, McHugh BJ, et al. Short- and long-term antibiotic treatment reduces airway and systemic inflammation in non-cystic fibrosis bronchiectasis. Am J Respir Crit Care Med 2012;186:657-65.

20 Jose RJ, Williams AE, Mercer PF, et al. Regulation of neutrophilic inflammation by proteinase-activated receptor 1 during bacterial pulmonary infection. J Immunol 2015;14:333-7.

21 Chalmers JD, Aliberti S, Polverino E, et al. The EMBARC European Bronchiectasis Registry: protocol for an international observational study. ERJ Open Res 2016;2:00081-2015.

22 Seumois G, Chavez L, Gerasimova A, et al. Epigenomic analysis of primary human $T$ cells reveals enhancers associated with TH2 memory cell differentiation and asthma susceptibility. Nat Immunol 2014;15:777-88.

23 Gibson GJ. Moran Campbell and clinical science. Thorax 2004;59:737-40.

24 Agusti A, Gea J, Faner R. Biomarkers, the control panel and personalized COPD medicine. Respirology2016;21:24-33. 
25 Agusti A, MacNee W. The COPD control panel: towards personalised medicine in COPD. Thorax 2013;68:687-90.

26 Steiner MC, Evans RA, Greening NJ, et al. Comprehensive respiratory assessment in advanced COPD: a 'campus to clinic' translational framework. Thorax 2015;70:805-8.

27 Shah A, Shoemark A, Macneill S, et al. S68 A longitudinal study characterising a large adult primary ciliary dyskinesia cohort. Thorax 2015;70:A40.

28 Lucas JS, Burgess A, Mitchison HM, et al. Diagnosis and management of primary ciliary dyskinesia. Arch Dis Child 2014;99:850-6.

29 Shah A, Kannambath S, Herbst S, et al. S82 'The Kiss of death'-calcineurin inhibitors prevent actin-dependent lateral transfer of Aspergillus fumigatus in necroptotic human macrophages. Thorax 2015;70:A48.

30 Adlakha A, Armstrong-James D, Lenhard B. S83 Calcineurin inhibition impairs phenotypic maturation of dendritic cells in an in vitro model of invasive aspergillosis in lung transplant recipients. Thorax 2015;70:A48-49.

31 Koustas S, Peel A, Scott J, et al. S84 Sputum neutrophils but not interleukin-8 (IL-8) or interleukin 17 (IL-17) correlate with the bronchiectasis severity index (BSI). Thorax 2015;70:A49.

32 Chalmers JD, Goeminne P, Aliberti S, et al. The bronchiectasis severity index. An international derivation and validation study. Am I Respir Crit Care Med 2014; 189:576-85.

33 Finch S, McDonnell MJ, Abo-Leyah $\mathrm{H}$, et al. A comprehensive analysis of the impact of Pseudomonas aeruginosa colonisation on prognosis in adult bronchiectasis. Ann Am Thorac Soc 2015:12:1602-11.

34 Khoo V, Pabary R, Lund Palau H, et al. S112 Variability in susceptibility to antibiotics and bacteriophages between individual colonies of Pseudomonas aeruginosa from cystic fibrosis sputum samples: implications for future clinical trial design. Thorax 2015;70:A64-65.

35 Mitchelmore P, Brown A, Sheldon C, et al. S113 An epidemiological review of strains of Pseudomonas aeruginosa in a non-cystic fibrosis bronchiectasis cohort. Thorax 2015;70:A65

36 Vallieres E, Tumelty K, Tunney M, et al. S115 Efficacy of Pseudomonas aeruginosa eradication regimens in non-CF bronchiectasis. Thorax 2015;70:A65-66.

37 José RJ, Periselneris JN, Brown JS. Community-acquired pneumonia. Curr Opin Pulm Med 2015:21:212-18.

38 Periselneris J, James T, Noursadeghi $\mathrm{M}$, et al. S86 The anti-inflammatory effects of pneumolysin. Thorax 2015;70:A49-50.

39 Trimble A, Collins A, Hancock C, et al. S70 Experimental human pneumococcal colonisation is an asymptomatic event in healthy adults. Thorax 2015:70:A41-42.

40 Chalmers JD, Taylor JK, Singanayagam A, et al. Epidemiology, antibiotic therapy, and clinical outcomes in health care-associated pneumonia: a UK cohort study. Clin Infect Dis 2011:53:107-13.

41 Nordmann P, Poirel L, Walsh TR, et al. The emerging NDM carbapenemases. Trends Microbiol 2011;19:588-95.

42 Tunney MM, Einarsson GG, Wei L, et al. Lung microbiota and bacterial abundance in patients with bronchiectasis when clinically stable and during exacerbation. $\mathrm{Am} J$ Respir Crit Care Med 2013;187:1118-26.

43 Sherrard LJ, Tunney MM, Elborn JS. Antimicrobial resistance in the respiratory microbiota of people with cystic fibrosis. Lancet 2014;384:703-13.

44 Sherrard LJ, McGrath SJ, Mcllreavey L, et al. Production of extended-spectrum $\beta$-lactamases and the potential indirect pathogenic role of Prevotella isolates from the cystic fibrosis respiratory microbiota. Int I Antimicrob Agents 2016;47:140-5.

45 Camberlein E, Cohen JM, José $\mathrm{R}$, et al. Importance of bacterial replication and alveolar macrophage-independent clearance mechanisms during early lung infection with Streptococcus pneumoniae. Infect Immun 2015:83:1181-9.

46 Singh SJ, Morgan MD, Scott S, et al. Development of a shuttle walking test of disability in patients with chronic airways obstruction. Thorax 1992:47:1019-24.

47 Kon SSC, Canavan JL, Nolan CM, et al. The 4-metre gait speed in COPD: responsiveness and minimal clinically important difference. Eur Respir J 2014;43:1298-305.

48 Vanfleteren LEGW, Spruit MA, Groenen M, et al. Clusters of comorbidities based on validated objective measurements and systemic inflammation in patients with chronic obstructive pulmonary disease. Am J Respir Crit Care Med 2013;187:728-35.

49 Bafadhel M, McKenna S, Terry S, et al. Acute exacerbations of chronic obstructive pulmonary disease: identification of biologic clusters and their biomarkers. Am J Respir Crit Care Med 2011;184:662-71.

50 Bafadhel M, McKenna S, Terry S, et al. Blood eosinophils to direct corticosteroid treatment of exacerbations of chronic obstructive pulmonary disease: a randomized placebo-controlled trial. Am J Respir Crit Care Med 2012;186:48-55.

51 Pascoe S, Locantore N, Dransfield MT, et al. Blood eosinophil counts, exacerbations, and response to the addition of inhaled fluticasone furoate to vilanterol in patients with chronic obstructive pulmonary disease: a secondary analysis of data from two parallel randomised controlled trials. Lancet Respir Med 2015:3:435-42.

52 Rigge L, Johnson M, Culliford D, et al. P20 A database approach to DOSE score calculation as a tool to identify 'at risk' chronic obstructive pulmonary disease patients through clinical records. Thorax 2015;70:A85.

53 Stone I, Khanji M, James W-Y, et al. P21 The applicability of current cardiovascular risk scores and cardiovascular surrogates in chronic obstructive pulmonary disease: a case-control study. Thorax 2015;70:A85-86.

54 Albarrati A, Gale N, Munnery M, et al. P22 Distribution and prediction of 10-years risk for coronary heart disease in COPD. Thorax 2015;70:A86

55 Ruickbie S, Prasad A, Jones P, et al. S123 Coronary atherosclerosis detected at elective angiography is more severe in people with COPD than in those without. Thorax 2015:70:A70.

56 Fisk M, Gale N, Mohan D, et al. S124 The BODE Index is an independent determinant of arterial stiffness in chronic obstructive pulmonary disease (COPD). Thorax 2015;70:A70-71

57 Saikia S, Gale N, Rodrigues J, et al. P23 Q/A METHOD—a novel way of assessing pulmonary artery stiffness in COPD using cardiac MRI. Thorax 2015;70:A87.

58 McKeever TM, Hearson G, Housley G, et al. Using venous blood gas analysis in the assessment of COPD exacerbations: a prospective cohort study. Thorax 2016;71:210-15

59 Alexandrov LB, Nik-Zainal S, Wedge DC, et al. Signatures of mutational processes in human cancer. Nature 2013;500:415-21.

60 Brahmer J, Reckamp KL, Baas P, et al. Nivolumab versus docetaxel in advanced squamous-cell non-small-cell lung cancer. N Engl J Med 2015;373:123-35.

61 Borghaei H, Paz-Ares L, Horn L, et al. Nivolumab versus docetaxel in advanced nonsquamous non-small-cell lung cancer. N Engl J Med 2015;373:1627-39.

62 Garon EB, Rizvi NA, Hui R, et al. Pembrolizumab for the treatment of non-small-cell lung cancer. N Engl J Med 2015;372:2018-28.

63 Camidge DR. Targeted therapy vs chemotherapy: which has had more impact on survival in lung cancer? Does targeted therapy make patients live longer? Hard to prove, but impossible to ignore. Clin Adv Hematol Oncol 2014;12:763-6.

64 Konstantinides SV, Torbicki A, Agnelli G, et al. 2014 ESC guidelines on the diagnosis and management of acute pulmonary embolism. Eur Heart $\lrcorner$ 2014:35:3033-69, 3069a-3069k.

65 Vanni S, Jiménez D, Nazerian P, et al. Short-term clinical outcome of normotensive patients with acute PE and high plasma lactate. Thorax 2015;70:333-8.

66 Hadinnapola C, Pepke-Zaba J. Developments in pulmonary arterial hypertensiontargeted therapy for chronic thromboembolic pulmonary hypertension. Expert Rev Respir Med 2015;9:559-69.

67 Jenkins D. Pulmonary endarterectomy: the potentially curative treatment for patients with chronic thromboembolic pulmonary hypertension. Eur Respir Rev 2015;24:263-71.

68 Vuylsteke A, Sharples L, Charman G, et al. Circulatory arrest versus cerebral perfusion during pulmonary endarterectomy surgery (PEACOG): a randomised controlled trial. Lancet 2011;378:1379-87.

69 Lang IM, Madani M. Update on chronic thromboembolic pulmonary hypertension Circulation 2014;130:508-18.

70 Gangoiti P, Camacho L, Arana L, et al. Control of metabolism and signaling of simple bioactive sphingolipids: implications in disease. Prog Lipid Res 2010;49:316-34.

71 Huang LS, Berdyshev EV, Tran JT, et al. Sphingosine-1-phosphate lyase is an endogenous suppressor of pulmonary fibrosis: role of S1P signalling and autophagy. Thorax 2015;70:1138-48.

72 World Health Organisation. Global tuberculosis report. 2013. http://apps.who.int/iris/ bitstream/10665/91355/1/9789241564656_eng.pdf (accessed 24 Dec 2015).

73 Meressa D, Hurtado RM, Andrews JR, et al. Achieving high treatment success for multidrug-resistant TB in Africa: initiation and scale-up of MDR TB care in Ethiopia —an observational cohort study. Thorax 2015;70:1181-8.

74 Greening NJ, Williams JEA, Hussain SF, et al. An early rehabilitation intervention to enhance recovery during hospital admission for an exacerbation of chronic respiratory disease: randomised controlled trial. BMJ 2014;349:94315.

75 Hopkinson NS, Englebretsen C, Cooley N, et al. Designing and implementing a COPD discharge care bundle. Thorax 2012;67:90-2.

76 Steiner M. Hospital admission and readmission for acute exacerbation of COPD. A tough nut to crack. Thorax 2015;70:1108-9.

77 Kon SSC, Jones SE, Schofield SJ, et al. Gait speed and readmission following hospitalisation for acute exacerbations of COPD: a prospective study. Thorax 2015;70:1131-7.

78 Greening NJ, Harvey-Dunstan TC, Chaplin EJ, et al. Bedside assessment of quadriceps muscle by ultrasound after admission for acute exacerbations of chronic respiratory disease. Am J Respir Crit Care Med 2015;192:810-16.

79 Hopkinson NS, Hart N, Jenkins G, et al. Embracing social media. Thorax 2015:70:1112. 